\title{
OS MODOS DE VIDA E A QUARENTENA DA CoViD-19
}

\author{
CoViD-19 ways of life and quarantine \\ CoViD-19 formas de vida y cuarentena
}

Received: october/2020

Accepted: november/2020

Available online: december/2020

Corina Alves Farinha, Mestre em Educação Tecnológica, Universidade do Estado de Minas

Gerais - UEMG - Unidade Abaeté, País: Brasil. E-mail: corina.farinha@gmail.com

\begin{abstract}
Resumo: Trata-se de metodologia de ensino-aprendizagem e pesquisa adotada na graduação em Administração em uma Instituição de Ensino Superior Pública embasada na questão: em que medida, na perspectiva discente, os modos de viver no âmbito familiar, educacional, profissional, lazer e sanitários sofreram mudanças em virtude da situação pandêmica declarada pela Organização Mundial da Saúde - OMS? Objetiva compreender os impactos da pandemia nos modos de pensar, agir e pensar dos acadêmicos na perspectiva teórica de Émile Durkheim. Os dados indicam que a pandemia impactou as relações sociais nas atividades escolares, provocando mudanças no estilo de vida, levando os estudantes a apresentar sentimentos de tédio e ansiedade. Assim, considerou-se relevante conhecer as mudanças, os sentimentos e perspectivas dos estudantes no contexto pandêmico.
\end{abstract}

Palavras-chave: Educação superior 1, Administração 2, Quarentena 3, Metodologia de ensino e aprendizagem 4.

Abstract: This is a teaching-learning and research methodology adopted in the undergraduate course in Administration at a Public Higher Education Institution based on the question: to what extent, in the student perspective, the ways of living in the family, educational, professional, leisure and health areas underwent changes due to the pandemic situation declared by the World Health Organization - WHO? It aims to understand the impacts of the pandemic on the ways of thinking, acting and thinking of academics in the theoretical perspective of Émile Durkheim. The data indicate that the pandemic impacted social relations in school activities, causing changes in lifestyle leading students to experience feelings of boredom, anxiety. Thus, it was considered relevant to know the changes, feelings and perspectives of students in the pandemic context. 
Keywords: Higher education 1, Administration 2, Quarantine 3, Teaching and learning methodology 4.

Resumen: Se trata de una metodología de enseñanza-aprendizaje e investigación adoptada en la carrera de Licenciatura en Administración de una Institución Pública de Educación Superior a partir de la pregunta: en qué medida, en la perspectiva del estudiante, las formas de vivir en el ámbito familiar, educativo, profesional, de ocio y de salud. sufrió cambios debido a la situación de pandemia declarada por la Organización Mundial de la Salud - ¿QUIÉN? Tiene como objetivo comprender los impactos de la pandemia en las formas de pensar, actuar y pensar de los académicos en la perspectiva teórica de Émile Durkheim. Los datos indican que la pandemia afectó las relaciones sociales en las actividades escolares, provocando cambios en el estilo de vida que llevaron a los estudiantes a experimentar sentimientos de aburrimiento y ansiedad. Así, se consideró relevante conocer los cambios, sentimientos y perspectivas de los estudiantes en el contexto de la pandemia.

Palabras clave: Educación superior 1, Administración 2, Cuarentena 3, Metodología de enseñanza y aprendizaje 4.

\section{INTRODUÇÃO}

Entende-se a sala de aula como local de ensino-aprendizagem e pesquisa ao ser adotada a metodologia da problematização da realidade e solução de problemas de Bordenave e Pereira (2012). Nesse sentido, a solução de problemas implica na participação ativa e no diálogo constante entre discente e docente de tal forma que a aprendizagem é concebida como a resposta natural do aluno ao desafio proposto. Assim, este trabalho objetiva compreender em que medida a pandemia da CoViD-19 impacta os modos de vida dos acadêmicos em Administração da Universidade do Estado de Minas Gerais - Unidade Abaeté.

A pesquisa se justifica em virtude da pandemia da CoViD-19 afetar as relações sociais em nível mundial. Uma vez que não se tem clareza dos impactos da quarentena sobre os modos de pensar, sentir e agir dos participantes desta pesquisa, torna-se pertinente a realização desta investigação. Compreende-se que os resultados poderão dialogar com pesquisas em andamento, como o survey, intitulado: Comportamentos e percepções globais 
na pandemia da CoViD-19 ${ }^{1}$, no qual uma equipe internacional de pesquisadores estuda comportamentos e percepções de cidadãos em situação pandêmica.

Assim, em 17 de março de 2020 foram ministradas as últimas aulas presenciais referentes ao primeiro semestre letivo do ano de 2020. A paralisação das aulas e fechamento das instituições de ensino foi uma das consequências da pandemia declarada pela Organização Mundial da Saúde devido ao vírus SARS-CoV-2² - Síndrome Respiratória Aguda Grave 2, causador da doença infecciosa CoViD-19³. Segundo a infectologista Eggo (BBC, 2020) ${ }^{4}$, uma situação pandêmica é a disseminação de uma doença infecciosa que apresenta um aumento do número de casos, seguido de um ponto máximo e, depois, uma diminuição. Uma pandemia não se caracteriza pela gravidade da doença que ela causa, afirma Ritchmann (BBC, $2020)^{5}$, mas pelo fator geográfico, quando todas as pessoas no mundo correm risco simultaneamente.

A retomada do semestre ocorreu em 27 de julho com aulas remotas por meio da Plataforma Microsoft Teams. Nesse contexto, considerou-se relevante abrir espaço para socialização de experiências vividas durante o recesso forçado das aulas. Assim, no primeiro encontro, problematizou-se a realidade trazendo à tona o tema da situação pandêmica, a quarentena e as mudanças nos modos de viver. Como recurso didático recorreu-se a dois vídeos (BBC NEWS BRASIL, 2020) e um texto (EL PAÍS, 2020). O primeiro vídeo, Coronavírus: o que significa a OMS declarar pandemia da nova doença, aborda as recomendações sanitárias a serem tomadas mundialmente perante a declaração de pandemia

\footnotetext{
${ }^{1}$ https://osf.io/3sn2k/ Global behaviors and perceptions in the Covid-19

${ }^{2}$ Denominação em inglês pela OMS: Severe acute respiratory syndrome coronavirus -2

${ }^{3}$ OMS - Coronavirus Disease 2019, anteriormente denominado de forma provisória "2019-nCoV" em Inglês: 2019 novel coronavírus

${ }^{4} \mathrm{O}$ que é pandemia e o que muda com declaração da OMS sobre o novo coronavírus https://www.bbc.com/portuguese/geral-51363153

${ }^{5}$ Idem nota de rodapé $n^{\circ} 3$
} 
pela OMS. O segundo vídeo, Coronavírus: impressionantes imagens em um mundo em quarentena, são mostradas, em um sobrevoo, diversas cidades, tradicionalmente lotadas de turistas, com ruas vazias devido a quarentena, e imagens das valas comuns destinadas aos sepultamentos das vítimas fatais da CoViD-19. Já o texto, Como o coronavírus vai mudar nossas vidas: dez tendências para o mundo pós-pandemia (SALAS, EL PAÍS, 2020) destaca as transformações provocadas pelo isolamento social e prospecta o cenário de um mundo pós-pandemia. O autor, analista de tendências, considera o coronavírus um acelerador de futuro, a provocar a aquisição de novos hábitos de consumo, de mudança nos valores e o impacto ambiental, do valor concedido às pessoas, do engajamento em uma causa, da reconfiguração dos espaços de comércio e os cuidados com a saúde. Dessa maneira, as atividades descritas, assistir aos vídeos e a leitura do texto, conduziram o discente à reflexão e problematização da situação pandêmica. Após essa etapa, os discentes realizaram duas atividades: uma didática, referente ao conteúdo do texto e vídeos e a outra de pesquisa, base de dados deste trabalho.

Para apreender o fenômeno pandêmico, optou-se pela Sociologia Clássica de Émile Durkheim (QUINTANEIRO; BARBOSA; OLIVEIRA, 1995), pois os estudos em torno das mudanças sociais por ele observadas, levaram ao entendimento de fato social. Um fato social é caracterizado pela presença e reconhecimento em uma sociedade; ocorre independente da vontade e os anseios do indivíduo e com uma força coercitiva capaz de moldar formas de pensar, sentir e agir. Tal entendimento pode ser relacionado aos acontecimentos verificados nos últimos dias do mês de dezembro de 2019, em que ao mundo capitalista contemporâneo apresentou-se um inimigo microscópico com uma potência destrutiva capaz de dilacerar o modelo de sociedade atual e determinar as condutas individuais. 
Uma série de casos de pneumonia de origem desconhecida na cidade de Wuhan, China, levou as autoridades chinesas a alertar a Organização Mundial da Saúde - OMS sobre o surgimento de um vírus, até então desconhecido pela ciência. O isolamento dos pacientes foi a medida tomada para conter a disseminação do vírus enquanto as primeiras análises indicavam a causa da doença a um novo coronavírus. De acordo com a OMS $(2020)^{6}$, a transmissão do vírus ocorre pelo contato humano com uma pessoa infectada. A doença pode se espalhar de pessoa para pessoa por meio de pequenas gotículas do nariz ou boca que se espalham quando uma pessoa com CoViD-19 toca ou exala. Essas gotículas pousam em objetos e superfícies ao redor da pessoa. Outras pessoas pegam o CoViD-19 ao tocar esses objetos e superfícies e depois tocando nos olhos, nariz ou boca. Outra forma de contágio é pela respiração de gotículas expelidas por uma pessoa contaminada. A prevenção é higiene frequente das mãos, evitar tocar o rosto e manter distanciamento de um a dois metros entre as pessoas, uso de álcool em gel, máscara protetora para o rosto, higiene das compras, vestuários e calçados.

Não havendo vacina e tão pouco medicamento específico para tratamento dos doentes, a medida internacionalmente adotada é a restrição à circulação e aglomeração de pessoas. Wuhan, capital da província de Hubei, China, ficou em quarentena, imposta pelas autoridades locais, entre 23 de janeiro à 08 de abril. Onze milhões de pessoas ficaram em casa, isoladas. Com o alto índice de disseminação do vírus em todo o mundo, diversos países adotaram medidas semelhantes, e em 8 de abril, metade da humanidade estava confinada, de uma forma ou outra, vivenciando uma crise sanitária mundial.

As medidas de confinamento para travar o contágio da CoViD-19 deixaram as ruas vazias. As pessoas recolheram-se às suas casas, as escolas fecharam, o comércio físico ${ }^{6}$ How does COVID-19 spread? $\underline{\text { https://www.who.int/news-room/q-a-detail/q-a-coronaviruses\#: :text=symptoms }}$ 
restringiu-se ao ramo alimentício, farmacêutico e de combustíveis; os aeroportos fecharam e reduziu-se o transporte terrestre; os parques industriais pararam. De um lado, os empresários e microempresários preocuparam-se com a continuidade dos negócios e, por outro lado, a insegurança passou a rondar os trabalhadores formais e informais. Entre o medo crescente dos que devem executar suas atividades em meio à pandemia há a sombra do desemprego a ameaçar milhões de pessoas. Tudo isso, são elementos que configuram um cenário de incerteza futura. Logo, em menos de três meses o agente patogênico SARS-Cov-2 modificara os hábitos cotidianos e desacelerava a economia, colocando os mundos da produção e do comércio, do trabalho e da vida em estado de alerta, numa quarentena sem prazo certo para acabar.

Assim, três bilhões de pessoas trancadas em casa recorrem à internet para estudar, trabalhar e lazer. A janela virtual permite, além do comércio eletrônico, e-commerce, aprendizado on-line, e-learning, dentre outras atividades remotas, tais como: casamento, consulta médica, atendimento psicológico, encontros religiosos, familiares, aniversários. Ganham relevância as informações científicas e as plataformas jornalísticas mundiais e canais de televisão, até então pagos, abrem acesso criando espaços específicos, divulgando e discutindo o extenso e diversificado volume de informações.

No âmbito educacional, à medida em que as escolas suspenderam as aulas presenciais, no exterior ${ }^{7}(\mathrm{OECD}, 2020)$ e no $\operatorname{Brasil}^{8}$ (G1, 2020.c), algumas instituições adotaram ensino em salas virtuais, em plataformas públicas e privadas, bem como, rádio, televisão, e aplicativos como Zoom. A transição de formato das aulas presenciais para virtuais exige

\footnotetext{
${ }^{7}$ https://www.weforum.org/agenda/2020/04/coronavirus-homeschooling-technology-oecd/ 8

https://g1.globo.com/educacao/noticia/2020/05/05/sem-internet-merenda-e-lugar-para-estudar-veja-obstaculos-d o-ensino-a-distancia-na-rede-publica-durante-a-pandemia-de-CoViD-19.ghtml
} 
adequação do plano e da metodologia de ensino. A elaboração de atividades e de vídeos exigem conhecimentos específicos, equipamento adequado e acesso à internet para professores e alunos. Nesse sentido, levanta-se o problema de acesso no Brasil. Segundo dados do IBGE, aproximadamente 46 milhões de brasileiros não têm acesso à rede. Dessa forma, a imprevisibilidade do final da pandemia e da retomada das aulas abre discussão sobre o cancelamento do ano letivo das escolas e do semestre para as universidades, bem como a preocupação com o aprofundamento das desigualdades educacionais e sociais.

Nas organizações públicas e privadas a situação pandêmica forçou o teletrabalho, exceto em casos imprescindíveis, para evitar a interrupção das atividades. O trabalho remoto, realizado em casa, exigiu compartilhamento do espaço físico, equipamentos, tecnologia com os demais moradores e adequações dos sons da casa, nem sempre possíveis, notadamente, para a realização de reuniões por videoconferência. Inevitavelmente, as atividades essenciais, submeteram o trabalhador ao risco de contágio. No mundo do trabalho emergiram diversas situações, tais como: repactuação de contrato, redução salarial e de horas trabalhadas, subempregos, compromisso dos empregadores em manter o contrato e milhões de desempregados no mundo todo.

A saúde física e mental das pessoas recolhidas em casa é impactada. As pessoas sofrem de tristeza por estarem sós ou porque não sabem o que o futuro as reserva, ou por que não conseguem suportar as famílias ou porque não tem recursos financeiros ou porque não tem trabalho (YEPES, 2020) ${ }^{9}$. Em diversos países aumentou o contingente de pessoas que precisam de ajuda durante a epidemia e há quem passe horas em uma fila para conseguir alimentos para a família. A crise sanitária é também uma crise social nas cidades e bairros populosos, uma vez que ficar em casa é deixar de trabalhar o que acentua as dificuldades. A

\footnotetext{
${ }^{9}$ https://www.youtube.com/watch?v=rapEnb-c0hk\&feature=youtu.be
} 
moradia de um ou dois cômodos é dividida entre a família com três ou mais integrantes. Assim, é improvável o controle do contato social para evitar o contágio e cuidados com higiene pessoal, notadamente, no Brasil, em que não há fornecimento de água canalizada para cerca de 18,4 milhões de brasileiros ${ }^{10}(\mathrm{G} 1,2020$ a).

A pandemia está trazendo à tona diferenças sociais em todo o mundo. O diretor-geral da OMS ressaltou: "Não estamos apenas analisando o impacto econômico da CoViD-19 em um país ou a perda do PIB. Temos que ver também o que isso significa para o indivíduo." (G1, 2020. b).

Nesse ponto, retoma-se a perspectiva de Durkheim (QUINTANEIRO; BARBOSA; OLIVEIRA, 1995) em que a sociedade precede os indivíduos e age sobre eles. O fato social pandêmico ocorre em nível mundial, imposto aos indivíduos e retirando a sociedade do seu funcionamento normal. Para evitar a anomia, ausência de regras e morte do organismo social, a contaminação das pessoas e proliferação do vírus, foram tomadas medidas extremas: a quarentena. Como os fatos sociais são formas de pensar, sentir e agir impostos aos indivíduos, as pessoas recolhidas às suas casas, veem alterar-se o curso de suas vidas, trabalho, lazer, família, amigos são laços sociais suspensos. Afastamento social, máscara, álcool em gel são novos hábitos a ser internalizados. A vida normal se tornara entediante. Sentimentos de medo, tédio, ansiedade e solidão fazem companhia às pessoas. No entanto, a garantia do funcionamento e continuidade da sociedade depende da cooperação entre as diversas instituições e do grau de coesão social. Esta pode ser observada no uso da internet a ligar indivíduos e profissionais, a dar um novo modo de viver em sociedade. O vírus invisível provocou uma mudança profunda nos relacionamentos humanos por meio da rede invisível da

10

https://g1.globo.com/economia/noticia/2020/05/06/cerca-de-184-milhoes-de-brasileiros-nao-recebem-agua-enca nada-diariamente-aponta-ibge.ghtml 
World Wide Web. A interdependência funcional encontrou formas para se manifestar: trabalhar, casar, estudar, adquirir produtos e serviços, consultas médicas, serviços governamentais. Redes sociais aproximaram famílias. O espaço da casa, ampliou-se, é lugar para recepcionar o mundo. E as janelas, lugar de sarau, agradecimentos e poesia. Porém, os limites das ações individuais permanecem limitados pelo fato pandêmico. A OMS, governos e sociedade exercem pressão social sobre os indivíduos para manter padrões de cuidados sanitários. O funcionamento da sociedade parece em um novo funcionamento. No entanto, antes que este se configure, indaga-se: em que medida, na perspectiva discente, os modos de viver no âmbito familiar, educacional, profissional, lazer e sanitários sofreram mudanças em virtude da situação pandêmica declarada pela Organização Mundial da Saúde - OMS?

\section{METODOLOGIA}

Trata-se de pesquisa exploratória, quantitativa, os dados, provenientes de questionário e pesquisa documental, submetidos à estatística descritiva. É um estudo de caso único. Estudos exploratórios proporcionam maior familiaridade com o fenômeno pesquisado, tornando-se úteis para diagnosticar, explorar alternativas ou descobrir novas ideias (GIL, 1999). A pesquisa quantitativa caracteriza-se pelo emprego da quantificação tanto coleta quanto no tratamento dos dados (RICHARDSON, 1999). Os estudos de caso investigam um fenômeno contemporâneo dentro do seu contexto de vida real, especialmente quando os limites entre o fenômeno e o contexto não estão definidos (YIN, 2001).

A instituição de ensino onde foi realizada a pesquisa é a Universidade do Estado de Minas Gerais, Unidade Abaeté, selecionada intencionalmente por facilidade de acesso às informações necessárias para a eficiência deste trabalho. A Universidade do Estado de Minas 
Gerais - UEMG foi criada pelo Art.81 do Ato das Disposições Constitucionais Transitórias da Constituição Mineira de 1989. O parágrafo primeiro do Art.82, do mesmo Ato, proporcionou às fundações educacionais de ensino superior instituída pelo Estado ou com sua colaboração, optar por serem absorvidas como unidades da UEMG. A Unidade Abaeté beneficia estudantes de nove cidades da região Biquinhas, Cedro do Abaeté, Dores do Indaiá, Ibitira, Martinho Campos, Morada Nova de Minas, Quartel Geral, Paineiras e Pompéu ofertando os seguintes cursos de graduação: Administração, Ciências Contábeis e Serviço Social.

Os dados quantitativos referem-se a aplicação de um questionário, disponível na Plataforma Microsoft Teams, Formulário Forms, com adesão voluntária de 84 discentes. Composto por seis questões abordando mudanças nos modos de vida, estilo de vida antes e durante a quarentena, sentimentos durante a quarentena, sentimentos no início da quarentena e em julho; prática de cuidados sanitários, e adoção de hábitos quando a quarentena finalizar.

\section{DADOS, ANÁLISE E CONSIDERAÇÕES}

Os dados disponibilizados são apresentados em seis âmbitos: 1. Impacto emocional em virtude do afastamento social; 2. A quarentena e as mudanças provocadas no estilo de vida; 3 . Estilo de vida dos participantes antes e durante a quarentena; 4. Adoção dos novos hábitos sanitários durante a quarentena; 5. Mudanças ocorridas durante a pandemia e permanência no futuro.

\section{Impacto emocional em virtude do afastamento social:}


A escola foi para todos os entrevistados o âmbito de maior mudança. 82 discentes (98\%) passaram a cuidar mais da saúde; 78 respondentes (93\%) concordaram sobre mudanças no lazer e 77 (92\%) nas amizades levando a 68 (81\%) ao modo de uso de aplicativos; alterações no âmbito familiar foi sentida por 64 discentes $(76 \%)$ e o trabalho mudou para 60 respondentes (71\%). No Gráfico 1 percebe-se que o âmbito escolar e saúde foram os mais afetados, refletindo a paralisação das aulas e cuidados sanitários. Lazer, amizade, uso de aplicativos, família e o trabalho foram menos impactados com a quarentena.

Gráfico 1 - Mudanças da rotina com a quarentena.

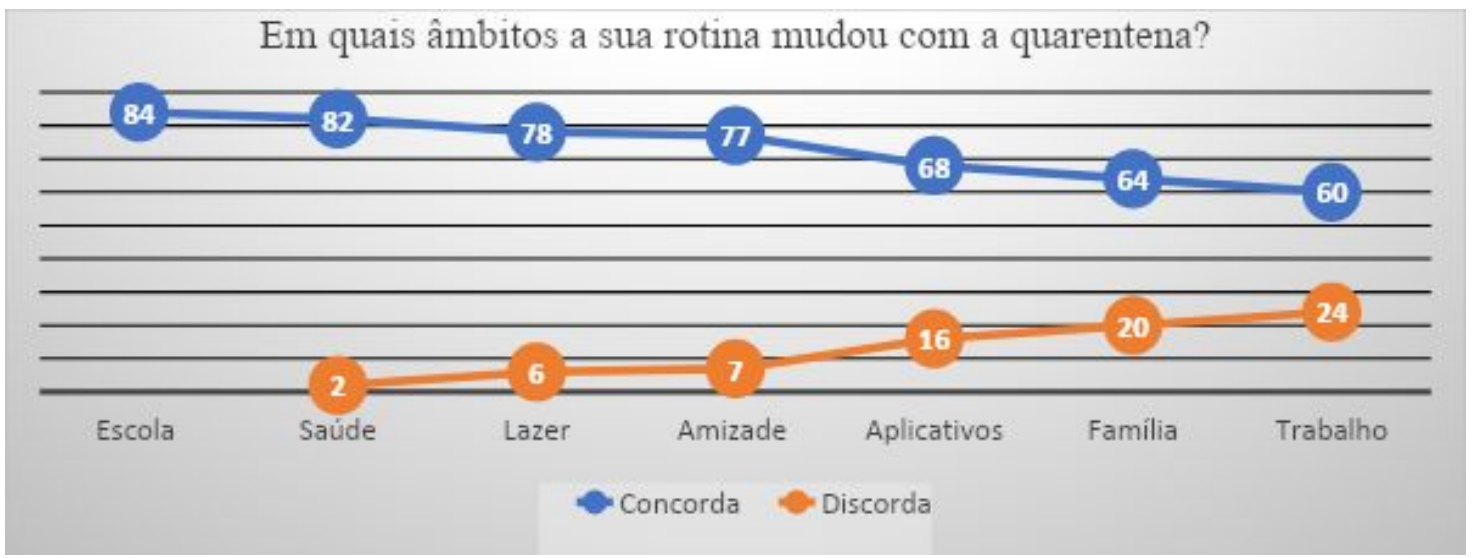

Fonte: A autora.

Esse contexto de mudança permite indagar sobre o estilo de vida dos discentes antes e durante a quarentena buscando assim uma correlação entre mudanças nos âmbitos das atividades: laboral, lazer, familiar, escolar verificando em que medida o estilo de vida foi alterado.

\section{A quarentena e as mudanças provocadas no estilo de vida}

Os dados indicam que antes da quarentena 39 discentes (46\%) consideravam a vida normal e satisfatória; 21 (25\%) dinâmica e agradável; 17 (20\%) animada e divertida; 06 (7\%) estressante e fatigante; e 01 entediante e aborrecida. Durante a quarentena 35 (42\%) 
consideraram que o estilo de vida passou a ser estressante e fatigante; 33 (40\%) entediante e aborrecida; 11 (13\%) consideraram normal e satisfatória; 3 (3\%) dinâmica e agradável e 2 (2\%) animada e divertida. Sobre o estilo de vida dos participantes antes e durante a quarentena os dados indicam: a normalidade das relações sociais propiciava um estilo de vida satisfatório, dinâmico e animado para os estudantes. A suspensão do contato social e físico, proveniente da paralisação das atividades escolares e lazer parece se revelar no estilo de vida estressante, fatigante, entediante e aborrecido, conforme demonstrado no Gráfico 2.

Gráfico 2 - Estilo de vida antes e durante a quarentena.

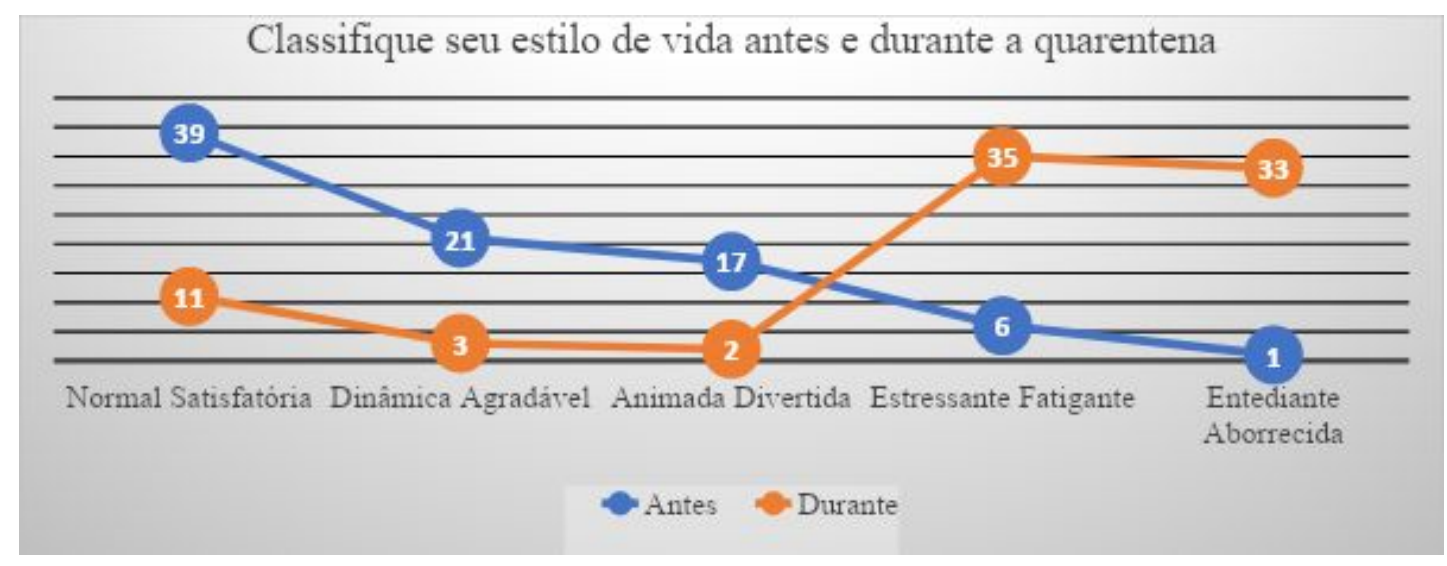

Fonte: A autora

Dessa forma, buscou-se conhecer em que medida o afastamento social gerou desconforto emocional aos discentes. O confinamento em casa, redução das atividades de lazer, encontros familiares e com amigos, paralisação das aulas, mudança no contato físico evitando a contaminação provocaram tédio e estresse em 69 discentes (82\%) e em 67 (80\%) ansiedade; em 63 (75\%) cansaço; em 53 (63\%) medo; em 50 (59\%) angústia; em 44 (52\%) tristeza e em 20 (24\%) solidão. Todavia, 56 (67\%) dos respondentes concordam que "este período vai passar" tédio, estresse, ansiedade, expressos pela maioria dos estudantes durante a quarentena, conforme demonstrado no Gráfico 3. Isto sugere possível relação com o estilo de 
vida estressante, fatigante, entediante, aborrecido conforme demonstrado no (Gráfico 2). Depressão, estresse, ansiedade pode ser as consequências do confinamento pelo estado de alarme devido à pandemia do coronavírus, aponta estudo de Rodríguez, Antino, Ruíz-Zorilla $\left(\right.$ UCM ES, 2020) ${ }^{11}$ em andamento na Universidade Complutense de Madrid (UCM ES) e colaboração com Sanz-Vergel University of East Anglia - UK com 2000 pessoas em 17 comunidades espanholas.

Gráfico 3- Sentimentos durante a quarentena.

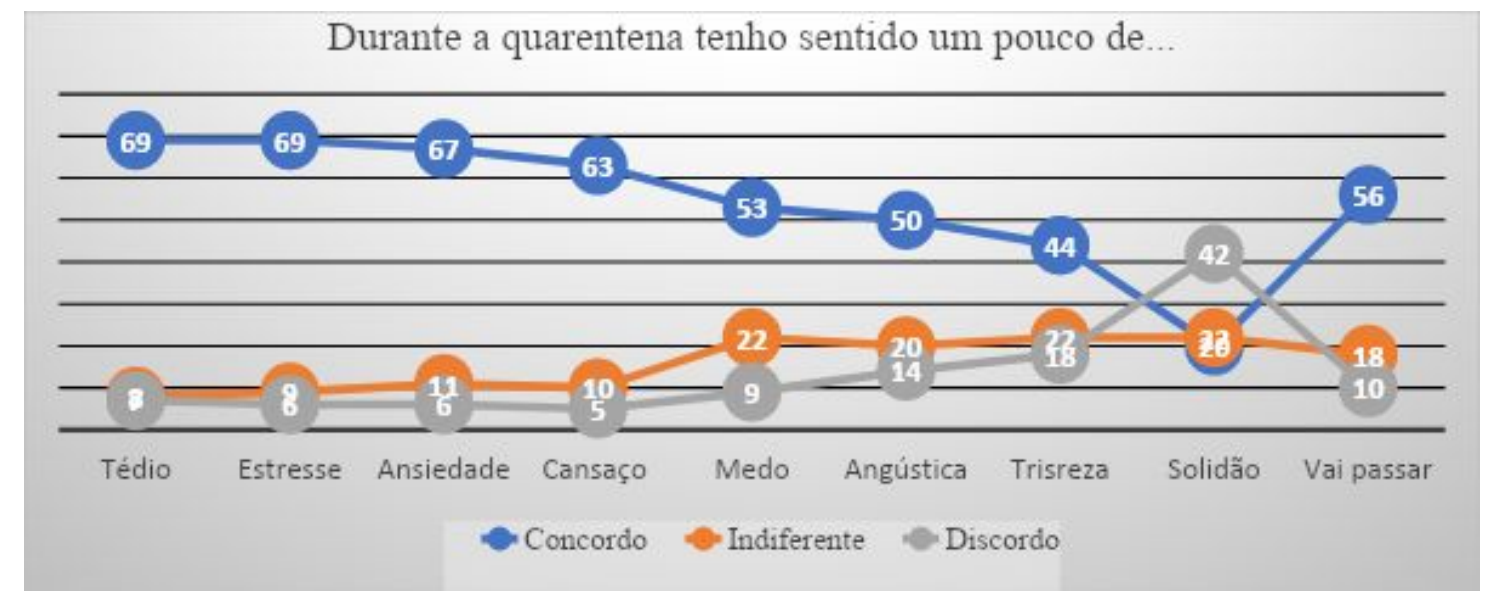

Fonte: A autora

\section{Estilo de vida dos participantes antes e durante a quarentena;}

A pesquisa identificou os sentimentos em dois períodos, no início da quarentena e quando da retomada das aulas, conforme demonstrado no Gráfico 4.

Gráfico 4 - Sentimentos em março e em julho de 2020.

https://www.ucm.es/depresion,-estres,-insomnio,-ansiedad\%E2\%80\%A6los-problemas-psicologicos-derivados-del-confina miento-podrian-perduran-meses-o-anos 


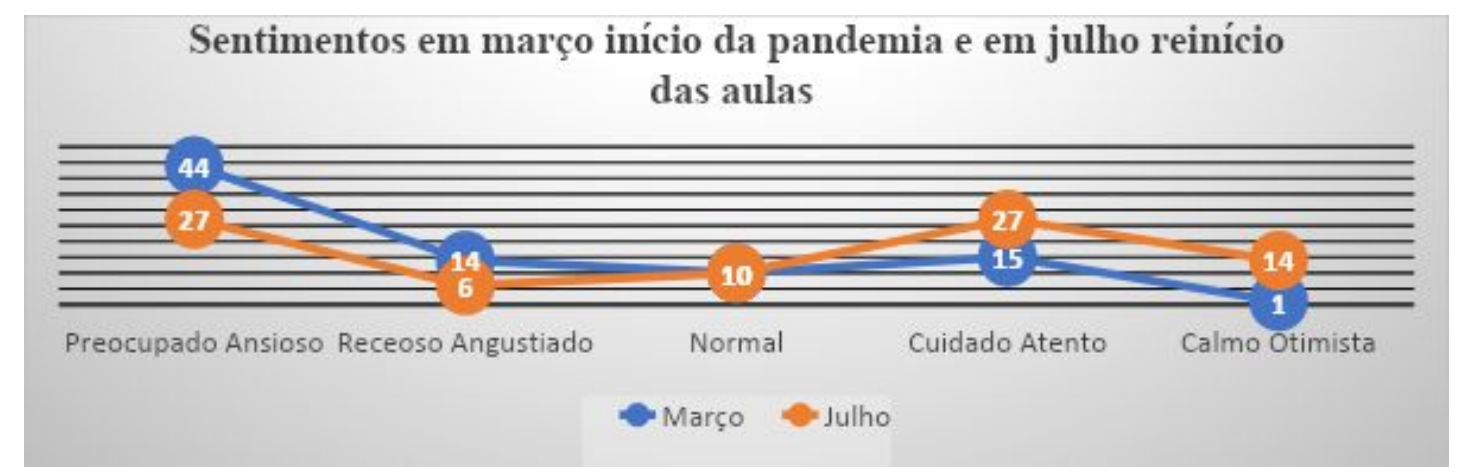

Fonte: A autora.

Os dados indicam que no início da quarentena 44 respondentes, $52 \%$, estavam preocupados e ansiosos; 15 (18\%) cuidadosos e atentos; 14 (17\%) receosos e angustiados; normais $10(12 \%)$ e 1 afirmou estar calmo e otimista. No mês de julho 27 discentes (32\%) demonstraram preocupação e ansiedade; 06 (7\%) receio e angústia; permanecendo estável o estado normal para $10(12 \%)$ e $27(20 \%)$ disseram estar cuidados e atentos e 14 (17\%) calmos e otimistas.

Conforme demonstrado no Gráfico 4, os estudantes sentiam-se, em grande parte, preocupados e ansiosos no início da quarentena, em março, no momento de interrupção das aulas; em julho, no início do ensino remoto, os dados indicam redução do número de tais sintomas pelos estudantes. Neste caso, evidencia-se a relação com a pesquisa de Rodríguez (UCM ES, 2020) e sua equipe da Universidade Complutense, Madrid, Espanha, em estudo sobre as consequências do confinamento. Os pesquisadores indicaram que na primeira semana da quarentena, foram observados maiores índices de ansiedade e depressão, bem como, estresse e problemas de sono. Etapas seguintes do estudo mostraram que a população se acostumou à situação de alarme prolongado causando recuperação nos sintomas.

\section{Adoção dos novos hábitos sanitários durante a quarentena}


A OMS ao declarar a situação pandêmica destacou medidas sanitárias para evitar a contaminação das pessoas com o vírus SARS-CoV-2. a menor atenção às práticas sanitárias, pode levar à anomia, ou seja, uma situação de ausência de regras e normas. A complexidade da doença, pode trazer consequências como disseminação, contaminação e até a morte.

A higiene frequente das mãos é adotada por 68 (81\%) dos respondentes; o uso de álcool em gel e máscara é adotado por 64 (76\%) dos respondentes; por outro lado a higiene das compras é às vezes adotada por $42(50 \%)$ e a não adoção por $32(38 \%)$ do cuidado com a higiene dos calçados ao entrar na residência parece demonstrar desconhecimento referente a duas formas de contaminação com o coronavírus em virtude de menor difusão das citadas práticas. Dos 84 respondentes, 67 (80\%) mostraram-se cuidadosos com a saúde, atentos aos sintomas da doença. Porém, dada a complexidade da doença torna-se relevante o esclarecimento aos estudantes a respeito do comprometimento com as recomendações da OMS. A participação ativa e consciente dos discentes é central para prevenir a exposição da comunidade acadêmica ao coronavírus em vista de uma possível retomada das atividades presenciais.

Gráfico 5 - Prática das recomendações sanitárias

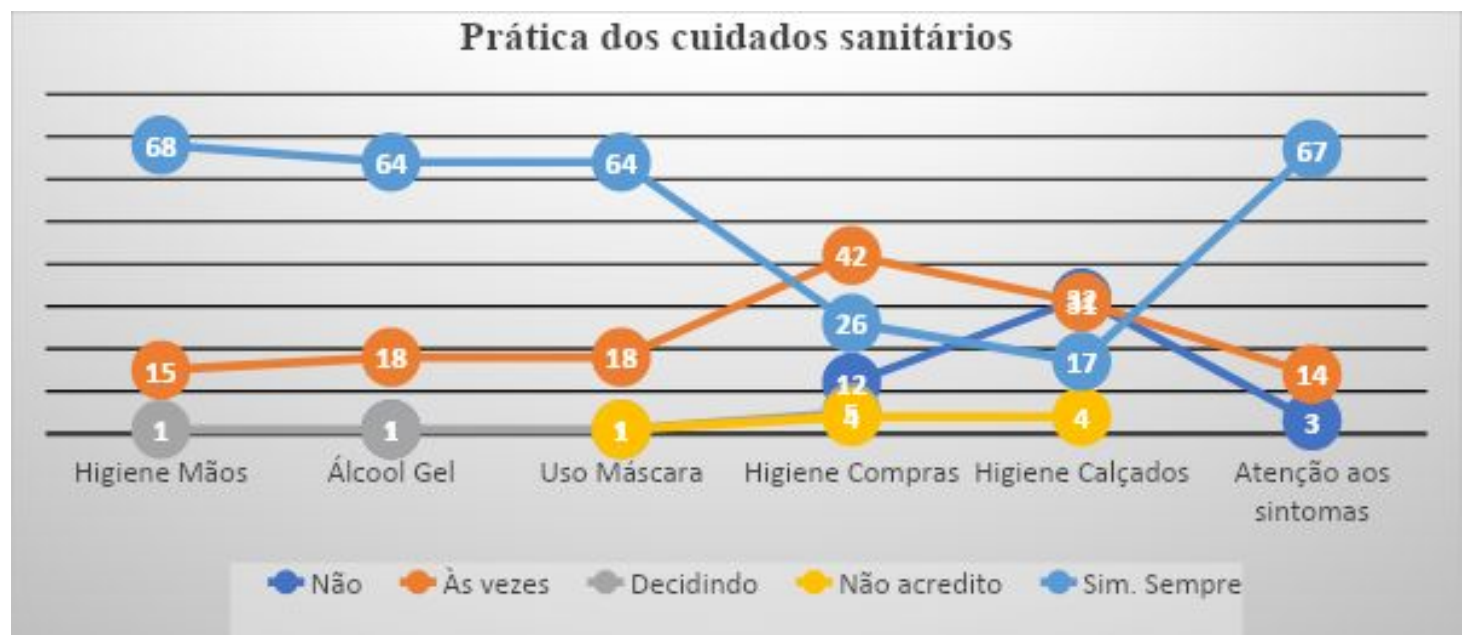

Fonte: A autora

5. Mudanças ocorridas durante a pandemia e permanência no futuro. 
Sobre a percepção discente sobre o futuro, abordando práticas adotadas na quarentena e que permanecerão pós-pandemia, os resultados sugerem reconfiguração da normalidade social na visão discente, conforme demonstrado no Gráfico 6.

Os dados indicam que $54(64 \%)$ dos discentes concordam que o consumo consciente permanecerá no mundo pós-quarentena; o trabalho remoto na percepção de 47 respondentes (56\%); 45 (54\%) concordam com a permanência do atendimento remoto de serviços públicos; $46(55 \%)$ discordam que o ensino remoto permanecerá e $53(63 \%)$ também discordam que as consultas médicas remotamente; uso de máscara não permanecerá na visão de $44(52 \%)$ dos discentes e para $71(85 \%)$ as ações solidárias permanecerão.

Gráfico 6 - Mundo pós-quarentena da pandemia da CoViD-19

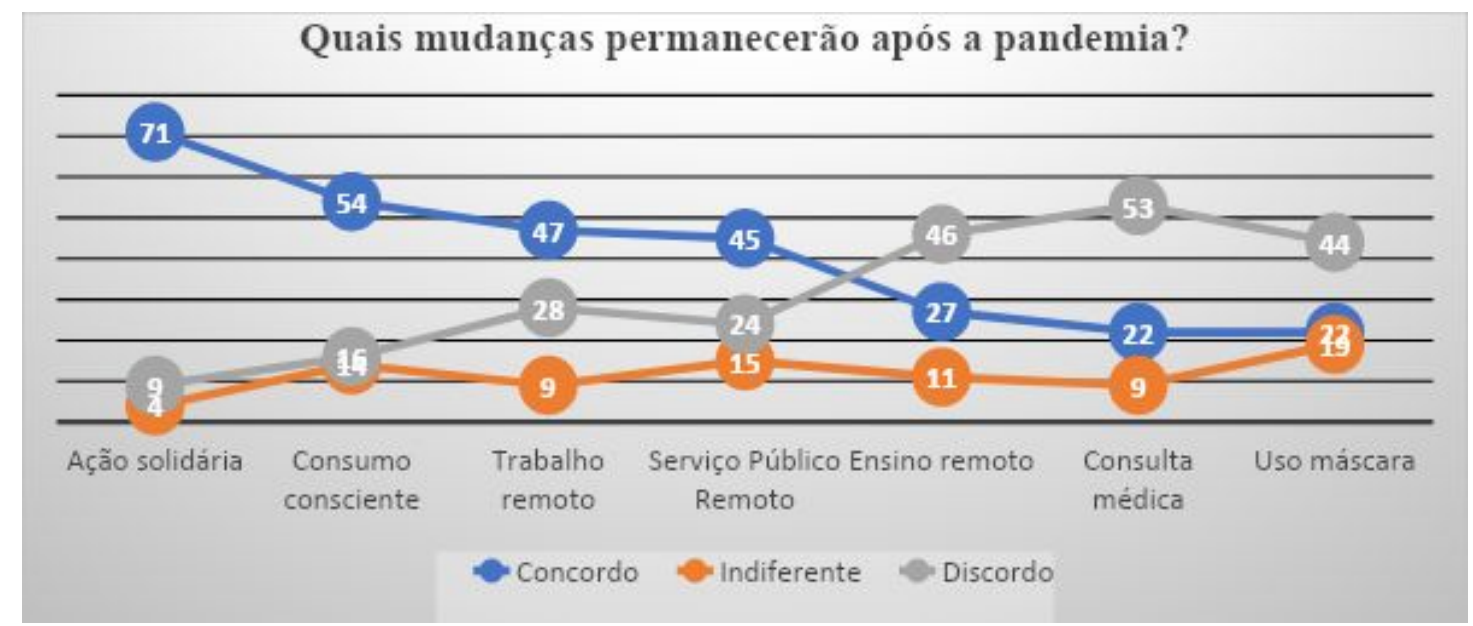

Fonte: A autora

Ações solidárias surgiram num contexto de fechamento de atividades de comércio, indústria, redução de postos de trabalho e impedimentos de autônomos e informais sair às ruas para ganho diário. O consumo consciente resulta da reflexão das consequências ao meio ambiente do capitalismo desenfreado. Em certo sentido as ações solidárias indicam a possibilidade de integração social. 


\section{CONSIDERAÇÕES FINAIS}

Considerar a situação pandêmica sob enfoque de Durkheim permite observar a força coercitiva da quarentena sobre os estudantes e, em que medida impingiu novas formas de pensar, sentir e agir a eles. Nessa perspectiva, entende-se que a ruptura do funcionamento normal da sociedade afetou o estilo de vida normal dos estudantes e ao tornar-se estressante, aborrecido, fatigante levou-os a sentirem tédio, ansiedade, medo e certa normalidade futura, isto vai passar. Com a quebra da regularidade dos padrões de sociabilidade, notadamente com a interrupção das aulas, os estudantes sentiram-se preocupados e receosos. Em julho, houve retomada do semestre em ensino remoto, embora número menor de estudantes mantivessem aqueles sentimentos; outra parte sentiu-se cuidadoso, atento e, em certa medida, calmo e otimista, de certa forma indica adaptabilidade à situação e restabelecimento de laços sociais em nova modalidade. Regras e normas sanitárias para evitar o contágio foram estabelecidas pela OMS à sociedade, e o grupo pesquisado demonstrou maior adesão à higiene frequente das mãos, uso de álcool em gel e uso de máscaras. No entanto, observou-se certa anomia em $20 \%$ dos estudantes. O funcionamento da sociedade pós-pandêmica, para a maioria dos estudantes, terá bases solidárias e consumo consciente, com atividades laborais e escolares híbridas e os indivíduos usando máscaras. Logo, a sociedade se refaz, reafirmando ideias coletivas constituindo sua unidade. Em trabalhos futuros, pretende-se investigar como se configuram os relacionamentos sociais, notadamente em trabalhos acadêmicos em equipe, em ensino remoto assemelham-se elou diferenciam-se do ensino presencial.

\section{REFERÊNCIAS}

BORDENAVE, Juan Díaz; PEREIRA, Adair Martins. Estratégias de ensino-aprendizagem. 32. ed. - Petrópolis, RJ : Vozes, 2012.

CERCA de 184 milhões de brasileiros não recebem água encanada diariamente, aponta IBGE. G1, 2020. Disponível em: $<<$ 
https://g1.globo.com/economia/noticia/2020/05/06/cerca-de-184-milhoes-de-brasileiros-nao-r ecebem-agua-encanada-diariamente-aponta-ibge.ghtml $>>$ Acesso em: 06 junho de 2020. (a)

COMO o coronavírus vai mudar nossas vidas: dez tendências para o mundo pós-pandemia. Brasil. El País. Disponível em: $<<$

https://brasil.elpais.com/opiniao/2020-04-13/como-o-coronavirus-vai-mudar-nossas-vidas-dez -tendencias-para-o-mundo-pos-pandemia.html $>$ Acesso em 13 abril 2020.

CORONAVÍRUS: o que significa a OMS declarar pandemia da nova doença. BBC News Brasil. Vídeo 1 (5:25'). disponível em: $<<$

https://www.youtube.com/watch?v=hxZpWYwNo5M $>>$ Acesso em: 30 março de 2020.

CORONAVÍRUS: impressionantes imagens em um mundo em quarentena. BBC News Brasil. Vídeo 2 (5:35'). Disponível em: $<<$

https://www.youtube.com/watch?v=1ItkCrbZhaE\&t=253s $>>$ Acesso em: 25 abril de 2020.

FETZER, T., et al.. Global Behaviors and Perceptions in the COVID-19 Pandemic. https://doi.org/10.31234/osf.io/3kfmh

GIL, A.C. Métodos e técnicas de pesquisa social. 5. ed. São Paulo : Atlas, 1999.

HOMESCHOOLING during the coronavirus pandemic could change education forever, says the OECD. OECD, 2020. Disponível em: $<<$

https://www.weforum.org/agenda/2020/04/coronavirus-homeschooling-technology-oecd/ $>>$. Acesso em: 30\04\2020.

OMS. How does CoViD-19 spread? Disponível em: $<<$

https://www.who.int/news-room/q-a-detail/q-a-coronaviruses\#: : :text=symptoms $>>$

Acesso em: 30 março de 2020 (a)

OMS reforça necessidade de isolamento social e testes para conter a velocidade das transmissões de Coronavírus. G1, 2020. Disponível em: $<<$

https://g1.globo.com/bemestar/coronavirus/noticia/2020/03/30/oms-reforca-necessidade-de-is olamento-social-e-testes-para-conter-velocidade-das-transmissoes-de-coronavirus.ghtml $>>$ Acesso em: 10 abril de 2020. (b)

O QUE é pandemia e o que muda com a declaração da OMS sobre o novo coronavírus. BBC. 2020. Disponível em: $<$ https://www.bbc.com/portuguese/geral-51363153 > Acesso em:

30 março de 2020.

QUINTANEIRO, T.; BARBOSA, M.L.O; OLIVEIRA, M.G. de. Um toque de clássicos:

Durkheim, Marx, Weber. Belo Horizonte : Editora UFMG, 1995.

RICHARDSON, R. J. Pesquisa Social: métodos e técnicas. $3^{\text {a }}$ ed. São Paulo : Atlas.

SALAS, J. Triste, generoso, apaixonado, sem dormir? Somos ratos de laboratório em um experimento natural. El País. Disponível em: 
$<<$ https://elpais.com/ciencia/2020-04-17/tristes-generosos-enamorados-insomnes-somos-rato nes-de-laboratorio-en-un-experimento-natural.html $\gg>$ Acesso em: 18\Abril $\backslash 2020$.

SEM internet, merenda e lugar para estudar veja obstáculos do Ensino a distância na rede pública durante a pandemia de CoViD-19. G1, 2020. Disponível em:

$<<$ https://g1.globo.com/educacao/noticia/2020/05/05/sem-internet-merenda-e-lugar-para-estu dar-veja-obstaculos-do-ensino-a-distancia-na-rede-publica-durante-a-pandemia-de-CoViD-19. ghtml $\gg$ Acesso em: 06 maio de 2020. (c)

UNIVERSIDAD COMPLUTENSE DE MADRID - Espanha. Disponível em:<< https://www.ucm.es/depresion,-estres,-insomnio,-ansiedad\%E2\%80\%A6los-problemas-psicol ogicos-derivados-del-confinamiento-podrian-perduran-meses-o-anos $>>$ Acesso em 30 outubro de 2020.

UEMG - Universidade do Estado de Minas Gerais . Disponível em: http://uemg.br/home/unidades . Acesso em 30 outubro de 2020.

YEPES, Carlos Padre. Misa de Hoy Eucaristía Digital Domingo 26 de Abril 20201 Papa Francisco. Vídeo 3 (53:18') Disponível em: << https://www.youtube.com/watch? $\mathrm{v}=$ rapEnb-c0hk\&feature=youtu.be $>>$ Acesso em: 26 abril de 2020.

YIN, R.K. Estudo de caso: planejamento e métodos. 2a ed. Porto Alegre : Bookman, 2001. 